\title{
THE 1995 NRC RATINGS OF DOCTORAL PROGRAMS: A HEDONIC MODEL
}

\author{
Ronald G. Ehrenberg \\ Peter J. Hurst
}

Working Paper 5523

\section{NATIONAL BUREAU OF ECONOMIC RESEARCH 1050 Massachusetts Avenue \\ Cambridge, MA 02138 \\ April 1996}

\begin{abstract}
Without implicating them for what remains, we are grateful to numerous colleagues at Comell for their comments on an earlier draft. This paper is part of NBER's research program in Labor Studies. Any opinions expressed are those of the authors and not those of the National Bureau of Economic Research.

(C) 1996 by Ronald G. Ehrenberg and Peter J. Hurst. All rights reserved. Short sections of text, not to exceed two paragraphs, may be quoted without explicit permission provided that full credit, including $(c)$ notice, is given to the source.
\end{abstract}




\title{
THE 1995 NRC RATINGS OF DOCTORAL PROGRAMS: A HEDONIC MODEL
}

\begin{abstract}
We describe how one can use multivariate regression models and data collected by the National Research Council as part of its recent ranking of doctoral programs Research-Doctorate Programs in the United States: Continuity and Change) to analyze how measures of program size, faculty seniority, faculty research productivity, and faculty productivity in producing doctoral degrees influence subjective ratings of doctoral programs in 35 academic fields. Using data for one of the fields, economics, we illustrate how university administrators can use the models to compute the impact of changing the number of faculty positions they allocate to the field on the ranking of their programs. Finally, we illustrate how administrators can "decompose" the differences between a department's rating and the ratings of a group of higher ranked departments in the field into difference due to faculty size, faculty seniority, faculty research productivity, and faculty productivity in producing doctoral students. This decomposition suggests the types of questions that a department and a university should be addressing if they are serious about wanting to improve the department's ranking.
\end{abstract}

Ronald G. Ehrenberg

New York State School of Industrial and Labor Relations Cornell University Ithaca, NY 14853-2801 and NBER
Peter J. Hurst

New York State School of Industrial and Labor Relations

Cornell University

Ithaca, NY 14853-2801 


\section{Introduction}

The recent National Research Council (NRC) rankings of doctoral programs in the arts, humanities, biological sciences, engineering, physical sciences and mathematics, and social and behavioral sciences has drawn considerable public attention. ${ }^{1}$ Because it is the first major assessment of doctoral education undertaken in over a decade, its findings have been highlighted in the national media. ${ }^{2}$ The study will undoubtedly be used by potential graduate students making application and acceptance decisions and by university administrators making resource allocation decisions. Thus, the study will influence, sometimes positively and sometimes negatively, doctoral programs at universities across the nation.

These rankings were obtained from a survey of over 16,700 graduate faculty members who were asked to rate each $\mathrm{PhD}$ program in their discipline on a scale of 0 (not sufficient for doctoral education) to 5 (distinguished). Each rater was provided with lists of the faculty members associated with each of 50 randomly chosen programs in the discipline and the number of new doctorates produced by each of the programs over the previous five-year period. Raters were asked to rate both the scholarly quality of each program's faculty and each program's effectiveness. The response rate to the survey was about 50 percent and the programs in each discipline were rated by at least 200 faculty members.

The NRC also collected a set of objective statistics about the seniority, research productivity, and productivity in producing doctoral degrees of program faculty. These data were not provided to raters. If one assumes, however, that raters were sufficiently knowledgeable about their profession that

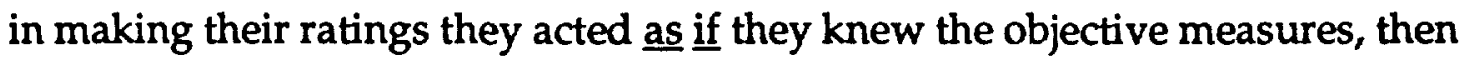


one can use multivariate regression models to estimate the extent to which variations in the objective measures influence raters' decisions. That is, one can estimate hedonic models of the determinants of departmental ratings. ${ }^{3}$ The resulting estimates can then be used to help guide resource allocation decisions at universities.

Why does one need such estimates? After all, the published NRC volume presented simple correlations between some of the objective measures and the subjective ratings of the raters. For example, program size, as measured either by the number of faculty associated with the program or the number of doctoral degrees granted by the program over the past five years, was shown to be positively correlated with the subjective ratings in most fields. However, when the objective measures are themselves correlated, as faculty size and degrees granted are, simple correlations do not permit one to learn the partial correlation of each objective variable with the subjective ratings. For example, they do not provide information about whether increasing faculty size, while holding constant the number of degrees granted, would be associated with a higher subjective rating. To answer such a question requires a multivariate analysis.

In this paper, we describe how one can use multivariate regression models and the NRC data to analyze how measures of program size, faculty seniority, faculty research productivity, and faculty productivity in producing doctoral degrees influence raters' subjective ratings of doctoral programs in various academic fields. Using data for one of the fields, economics, we then indicate how university administrators can use the models to compute what the impact of adding one faculty position would be on the ranking of an economics department. The department chosen to illustrate the methodology is the Cornell economics department in which one of us has an appointment. Finally, we illustrate how administrators can "decompose" the differences between a 
department's rating and the ratings of a group of higher rated departments in the field into differences due to faculty size, faculty seniority, faculty research productivity, and faculty productivity in producing new doctorates. To illustrate the methodology we use the Cornell economics department and choose the top ten economics programs as the comparison group. This decomposition suggests the type of questions that the department and university should be addressing if they are serious about wanting to improve the department's ranking.

The methodology that we describe in the next section, statistically relating an outcome (in this case the subjective rating) to a set of objective measures and then inferring the effect of a change in any of the latter on the outcome, has a long tradition in economics. As noted above, it is commonly referred to as the "hedonic function" or "implicit price" approach. Implicit in the approach is the assumption that one can infer causality from such cross-section estimates. While there are other methodological approaches that are more appropriate for trying to infer causality when longitudinal or panel data are available, in the absence of these types of data we are restricted to the approach presented here. Hence, in what follows, we will assume in places that we can infer how a given change in any one of the objective measures would quantitatively influence a program's subjective rating. Readers unhappy with this assumption can view our work as purely descriptive.

\section{Methodology}

Table 1 presents data for Cornell University's doctoral program in economics on its scholarly quality of program faculty rating and some of the

objective measures collected by the NRC. On a scale of 0 to 5 , the mean rating of Cornell's economics department in terms of scholarly quality of the faculty was 3.56 in 1993 which ranked it as the 18th best department in the nation. 
Economics is also one of Cornell's lower ranked doctoral programs, as most of Cornell's humanities, engineering, and physical science programs are ranked in the top ten nationwide in their fields. ${ }^{4}$ Cornell's economics program faculty members also made it only the 29th largest economics department.

The other variables displayed in table 1 are not always in the form collected and presented by the $\mathrm{NRC}^{5}$. Rather, some have been transformed to reduce multicollinearity (correlations among the objective variables) in the analyses that follow. For example, rather than listing the number of doctoral degrees granted by the field during the previous five years, which is highly correlated across programs with faculty size, we list doctoral degrees granted per faculty member during the previous five years. These transformations have been made because high levels of multicollinearity lead to large standard errors and imprecise coefficient estimates.

With data on these variables in table 1 for each doctoral program in each field, one can estimate for each field models of the form:

$$
\text { (1) } R_{1}=a_{0}+a_{1} F_{1}+a_{2} F_{i}^{2}+\sum_{j=3}^{8} a_{i} x_{j 1}+\varepsilon_{i}
$$

Here $R_{i}$ is the rating of the scholarly quality of the faculty at institution $i$; $F_{i}$ is the number of faculty associated with the doctoral program at institution $i$, the $x_{j i}$ are the other objective characteristics assumed to influence program ratings (to be discussed shortly), $\varepsilon_{\mathrm{i}}$ is a random error term, and the $a_{j}$ are the parameters to be estimated. 6

The estimated values of these parameters provide estimates of the marginal impact of a one-unit change in each objective variable on the subjective rating the doctoral program received, holding constant all other variables. The squared faculty size variable permits the relationship between rating and faculty 
size to be nonlinear. In particular, the marginal effect of an increase in faculty size by one on the faculty program rating, holding all the other variables in the model constant, is given by

$$
\text { (2) } \mathrm{a}_{1}+2 \mathrm{a}_{2} \mathrm{~F}_{\mathrm{i}} \text {. }
$$

As a result, if $a_{1}$ proves to be positive and $a_{2}$ proves to be negative, as faculty size increases the program rating will first increase, but at a declining marginal rate. The rating will eventually reach a maximum at a faculty size equal to minus $a_{1} / 2 a_{2}$. Finally, the rating will decline as program size continues to increase beyond this faculty size.

The other variables (the $x ' s$ ) included in the analyses are the percentage of full professors (FULL), the percentage of program faculty with external research support (RESEARCH), publications per faculty member (PUBFAC), a measure of the dispersion of publications per faculty member, the GINI coefficient for publications per faculty member (GINIPUB), the number of citations per faculty publication (CITEPUB), the number of $\mathrm{PhD}$ degrees granted per faculty member (PHDFAC), the number of PhDs granted per enrolled graduate student (PHDSTU) and the median number of years that it took new doctorates to receive their degrees (MEDTIME). ${ }^{7}$ Publication data were not collected by the NRC for faculty in the arts and humanities. Hence, for these fields PUBFAC, GINIPUB, and CITPUB do not appear in the analyses. Instead, the NRC collected data for these fields on the total number of prestigious awards and honors won per faculty member (AWARDF), and this variable is included in the models for these fields. Implicit in the set of variables included in the model is the belief that the raters subjective ratings of a program are determined by the program's size, the seniority distribution of its faculty, its faculty members' research productivity, and their doctoral production productivity. 


\section{Empirical Estimates}

The estimated regression coefficients for each field that we obtained are found in tables $2 \mathrm{~A}$ to $2 \mathrm{E} .^{8}$ In all fields but one, there is a positive relationship between program rating and faculty size (FACULTY). However, typically, the coefficient of the square of faculty size (FACULTY2) is negative, implying that after some faculty size, further growth has a negative effect on ratings. ${ }^{9}$ In most fields (but not in the majority of the biological sciences), increases in the proportion of faculty who are full professors (FULL) leads to higher ratings, presumably because cumulative accomplishments and name recognition are higher for full professors.

The three measures of faculty research productivity (RESEARCH, PUBFAC, CITPUB), all tend to be positively associated with the subjective ratings. In contrast, the dispersion in faculty productivity, GINIPUB, is statistically significantly negatively associated with ratings in the majority of fields. Since an increase in GINIPUB means an increase in dispersion, this implies that hiring both a "star" and a "lemon" whose average productivity is the same as that of existing faculty may decrease program ratings in these fields! In the arts and the humanities, the objective measure of faculty productivity. (AWARDF) also is positively associated with the subjective ratings.

Measures of doctoral program success also matter. In about two-thirds of the fields, the greater the number of doctoral degrees produced per faculty member (PHDFAC), the higher the ratings tend to be. This implies that increasing the number of faculty associated with a program, without also increasing the number of degrees granted, will indirectly have a negative effect on program ratings in these fields. Finally, longer median times to degree (MEDTIME), which within a field typically are associated with programs with less financial support per graduate student, are also associated with more poorly 
rated programs. ${ }^{1011}$

\section{Implications}

We return to the field of economics, and in particular Cornell's program, to illustrate how the estimates we obtained may be used to help guide university decision-making. As table 3 indicates, Cornell's economics program included 30 faculty in 1993 while the average program size of the top ten departments in economics was 38 that year. Not unexpectedly, the Cornell department has argued over the years that it needs more faculty positions if it is to improve its ranking. Faced with tight budgets, the institution as a whole alternatively wonders how much the department would be hurt if it lost a position.

One can, in fact, conduct simulations of what the impacts of increasing, or decreasing, the faculty resources devoted to the Cornell economics program by one faculty member, all other variables held constant (including $\mathrm{PhDs}$ produced per faculty member) would be on Cornell's ranking in the field. The answers to these questions depend upon the magnitudes of the estimated coefficients of faculty size and faculty size squared, and the number of faculty currently associated with the program, which together through the expression in (2) determine what the change in Cornell's absolute rating would be predicted to be. How tightly bunched the ratings of other programs are around the Cornell program then determines how this change would translate into a change in the Cornell program's relative ranking. 
When these simulations were conducted, they indicated that Cornell economics would improve its relative rank by one if it received an additional faculty line and would similarly reduce its relative rank by one if it lost a position. 12 These simulations assume, of course, that all of the other "explanatory" variables in the model would remain unchanged. If any of them would change as a result of a change in faculty size, the impact of these changes would have to be included in the simulations.

For example, if the number of PhDs granted per faculty member declined when faculty size increased because there was no increase in support for graduate students, this indirect negative impact would also have to be included in the computation of the change in the ranking.

It should also be noted that larger changes in faculty size will not necessarily lead to simulated proportionately larger changes in a department's relative ranking. This is because the predicted change in the ranking depends both on the predicted change in the rating and the number of schools whose ratings are "closely bunched" around the department. Unless the distribution of program ratings is uniformly distributed, the change in a program's ranking will not necessarily be proportionate to the change in its rating.

The estimated coefficients for economics can also be used to estimate what percentage of the difference between the average absolute rating of the top ten economics departments and Cornell's economics department absolute rating can be "explained" by each of the variables in the model. Given the estimated coefficients $\hat{\mathbf{a}}_{j}$ for a field, the predicted absolute rating of Cornell's program, $\hat{\mathbf{R}}_{c}$, is given by

$$
\text { (3) } \hat{\mathrm{R}}_{\mathrm{c}}=\hat{\mathrm{a}}_{0}+\hat{\mathrm{a}}_{1} \mathrm{~F}_{\mathrm{c}}+\hat{\mathrm{a}}_{2} \mathrm{~F}_{\mathrm{c}}{ }^{2}+\sum_{j=3}^{8} \hat{\mathrm{a}}_{\mathrm{i}} \mathrm{x}_{\mathrm{j}}
$$

Similarly, given the means of the characteristics of the top ten schools, the 
predicted absolute rating for the mean of the top ten schools, $\hat{\mathrm{R}}_{\mathrm{m}}$, is given by

$$
\hat{R}_{m}=\hat{a}_{0}+\hat{a}_{1} F_{m}+\hat{a}_{2} F_{m}{ }^{2}+\sum_{j=3}^{8} \hat{a}_{j} x_{j m}
$$

Here the subscripts $c$ and $m$ refer to the values for Cornell and the mean of the top ten schools, respectively, of each of the variables.

The predicted absolute difference in the rating of Cornell and of the mean of the top ten schools that is due to differences in faculty size is thus given by

(5a) $\hat{a}_{j}\left(F_{m}-F_{c}\right)+\hat{a}_{2}\left(F_{m}{ }^{2}-F_{c}{ }^{2}\right) \cdot \cdot^{13}$

Similarly, the predicted absolute difference due to differences in any of the other explanatory variables is given by

(5b) $\hat{a}_{j}\left(x_{j m}-x_{j k}\right) \quad j=3,4, \ldots 8$.

To obtain an estimate of the percentage of the actual difference that is "due" to each explanatory variable, one simply divides the estimates from (5a) or (5b) by the actual observed difference, $R_{m}-R_{c}$, and then multiplies the result by one hundred. The percentage of the actual difference that is due to all of the explanatory remarks is obtained by summing the percentages due to each variable.

The estimates obtained from performing such calculations for the Cornell field of economics are summarized in rows 16 and 17 of table 3 . Row 17 indicates that 87 percent of the difference between the average rating of the top ten programs in economics and the Cornell economics department's program rating is explained by all of the variables in the model.

Row 16 indicates how this explained percentage can be divided across sets of explanatory variables. About one-third, or 28 percent, is due to Cornell's having a smaller faculty size than the average top ten program. 37 percent is due to Cornell's economists having lower research productivity than the economists at the top ten programs, as measured by the percentage of faculty with research 
grants, publications per faculty member and citations per publication. Finally, 23 percent is due to Cornell's faculty having lower productivity in doctoral student production, as measured by fewer doctoral students produced per faculty member and longer times-to-degree per student. Crucially, although a smaller faculty size is one of the contributing factors to Cornell's not being ranked among the top ten economics departments, it is not the major factor. Rather, the major factor is the lower research productivity of its faculty.

The fact that Cornell's economists' research productivity, as measured primarily by publications per faculty member and citations per publication, is lower on average than the research productivity of faculty at the top ten economics programs should of course be of concern to the university. Does it reflect an inability to attract the very best young scholars? Does it reflect that Cornell's faculty in economics spend more time on teaching and less time on research than their colleagues do at the top ten competitor institutions? Does it reflect a propensity by Cornell to promote a much higher proportion of assistant professors than its competitors in economics, and thus the need to revise tenure standards? If it is a failure of Cornell to attract the very best faculty in economics, is this because of the relatively low level of salaries that Cornell pays its senior faculty or because of its unwillingness to pay a compensating wage differential to attract top faculty to relatively weaker departments in the University such as economics? ${ }^{14}$ A university interested in improving the ranking of a department needs to know the answers to such questions. 


\section{FOOTNOTES}

1. Marvin L. Goldberger, Brendan A. Maher, and Pamela Ebert Flattau eds Research Doctorate Programs in the United States: Continuity and Change. National Academy Press. Washington DC: 1995.

2. See, for example, Denise K. Magner "Doctoral Judgements: A Sweeping National Study Assesses the Quality of Research Programs in 41 Fields"; Chronicle of Higher Education, September 22, 1995, A20-A30., William Honan "Study of Graduate Programs Serves up Several Surprises", New York Times 44(September 13, 1995): Al, and Amy Wallace "UC Berkeley Ranked First in PhD Programs", Los Angeles Times 114 (September 13, 1995): A1.

3. See Sherwin Rosen "Hedonic Prices and Implicit Markets", Lournal of Political Economy 82 (Jan/Feb 1974): 34-55.

4. In what follows, our focus is on the scholarly quality of the faculty rating. Similar analyses to those described here could obviously be done for the program effectiveness rating. Potential students and university administrators presumably use both ratings in their decision calculus.

5. The raw data for each school for each field are found in Appendix tables J, K, $\mathrm{L}, \mathrm{M}$, and $\mathrm{N}$ of Goldberger et al. (1995). They are also available in the form of EXCEL spreadsheets from The National Research Council's World Wide Web site, from which they can be downloaded. 
6. The quality of program faculty variable, $R_{\mathfrak{i}}$ can only vary between 0 and 5 . Since the linear model in equation (1) places no such restrictions on the predicted value of the outcomes, it is clearly not formally appropriate. A model that avoids the problem of the limited range of $R_{j}$ is a variant of the logit model

(1a) $\quad \log \left(R_{i} /\left(5-R_{i}\right)\right)=b_{0}+b_{1} F_{1}+b_{2} F_{1}^{2}+\sum_{j=3}^{8} b_{j} x_{j i}+u_{1}$

Here one must assume that the error term, $u_{i}$, is lognormally distributed, and $\log$ represents the natural logarithm. Note that when $R_{i}$ equals zero the dependent variable in (1a) takes on the value of minus infinity, while when $\mathbf{R}_{\mathbf{i}}$ equals 5 , the dependent variable takes on the value of infinity.

We use equation (1) throughout this paper primarily for expositional convenience. It should be viewed only as a linear approximation to the true nonlinear model. If one were to seriously consider basing resource allocation decisions on the analyses we present in the paper, it would be necessary to see how sensitive our results are to the functional form assumptions. In the appendix, we provide estimates of (la) for economics and illustrate that our specific simulations do not change when this functional form is used.

7. The GINI coefficient is a measure of dispersion. If all faculty members in a program had the same publication level, the GINI coefficient for publications per faculty member would be equal to zero for that program. The greater the dispersion in publications per faculty member, the higher the GINI coefficient will be. For a discussion of how GINI coefficients are calculated, see Goldberger et al. (1995), p. 56. 
8. Estimates were obtained for 35 of the $\mathbf{4 1}$ fields. The excluded fields were ones in which Cornell had no program.

9. Models were estimated that both included and excluded the square of faculty size as an explanation variable. If the coefficient of the square of the faculty size variable did not prove to be statistically significantly different from zero at the .10 level (one-tail test), the model that excluded the square of faculty size is reported in Table 2. As noted above, the negative coefficient of faculty size squared in most fields imply that there is a faculty size in each of those fields that maximizes program rating. However, when computed, these sizes often are larger than the largest program observed. Given the dangers inherent in making projections outside the range of the data observed, we do not report these "optimum" program sizes here.

It may seem strange to talk about significance tests because the observation sets typically consisted of all graduate programs in a field, not just a sampling of programs. However, the ratings themselves are random variables because they come from a sample of raters (typically around 100 per program) and thus contain sampling error.

10. Evidence on the relationship between financial support patterns and time-todegrees is found in Ronald G. Ehrenberg and Pangioths Mavros "Do Doctoral Students' Financial Support Patterns Affect Their Times-to-Degree and Completion Probabilities", Journal of Human Resources, Summer 1995.

11. In the few cases that PHDSTU, the ratio of number of doctorates produced 
during the 1988-1992 period to the number of graduate students enrolled in 1992, was statistically significantly related to the program ratings, the relationship tended to be negative. One interpretation of this finding is that larger values of PHDSTU occur when program size has been contracting and contracting programs are usually not highly rated.

12. The quality of faculty ratings for the 16 th through 20 th ranked programs in economics are, respectively, California-LaJolla (3.80), New York University (3.62), Cornell (3.56), California Institute of Technology (3.54), and Maryland College (3.46). Using expression (2) in the text (the relevant coefficients from table $2 \mathrm{~A}$, and Cornell's program size of 30 faculty, a change in faculty size of one, other factors held constant, would change Cornell's rating by $.097+30(-.000953)$ or about .06 . Hence an increase in one faculty position is predicted to raise Cornell's rating to about 3.62, moving it into a tie for the 17th rank with NYU. A loss of one position is predicted to reduce Cornell's rating to 350, dropping it below Cal Tech into the 19th rank. Given the standard errors associated with each of the regression coefficients, as well as the sampling variability in the ratings, such simulations should be viewed as only suggestive of what is likely to happen. One should not interpret these simulations as implying that we believe faculty resources should be allocated primarily based on graduate program ranking. Faculty resource allocation decisions clearly should be based on many factors other than graduate program rankings, including undergraduate and graduate teaching needs, costs of faculty in the various fields, and the perceived relative importance of the various fields to the university.

13. For fields in which faculty size does not appear in quadratic form, the second 
term in $(5 a)$ is omitted.

14. Paradoxical to most noneconomists, is that the weaker a department is, the higher the salary that must be paid to talented faculty to attract them to the department. Put another way, to the extent that potential faculty value good colleagues, the better the department, the lower the salary they should be willing to accept. Thus, if market salaries did not differ across fields, one should observe a negative correlation between salaries in a field and departmental quality within a university. 


\section{APPENDIX}

Appendix table 1 provides estimates of the variant of the logit model found in equation (ia) for the field of economics. A comparison of the equations for economics found in table $2 \mathrm{~A}$ and in appendix table 1 indicates that the patterns of signs and statistical significance of the coefficients in the two models is virtually identical. When the coefficients from appendix table 1 are used in an analogous fashion as described in the text and footnote 12 to estimate the impact on Cornell's ranking of changing its economics department's size by one, identical results to those in the text are obtained. That is, other variables held constant, an increase (decrease) of faculty size by one faculty member would improve (worsen) the Cornell department's relative ranking by one.

Appendix table 2 uses the model found in appendix table 1 to partition the explained difference between Cornell's program's faculty quality rating and the average faculty quality of the top 10 economics programs into percent shares due to faculty size, faculty seniority, faculty research productivity, and faculty productivity in producing new doctorates. When the logit model is used, 70 percent of the difference is "explained" by the model. This 70 percent can be decomposed into 17 percent due to faculty size, 30 percent due to faculty research productivity and 23 percent due to faculty productivity in producing new doctorates. Consistent with the results from the linear model reported in the text, differences in faculty research productivity between Cornell and the top ten schools is again seen to be the most important reason that Cornell's program is not rated in the top 10 in terms of faculty quality. 
Table 1

1993 NRC Cornell Economics Program Characteristics

(Cornell rank among institutions)

\begin{tabular}{|lrl|}
\hline & \multicolumn{1}{l|}{ Economics } \\
\hline Variable & & \\
\hline FACQUAL & $3.56(18)$ \\
FACULTY & $30(29)$ \\
FULL & $70 \%(13)$ \\
RESEARCH & $33 \%(9)$ \\
PUBFAC & $3.1(37)$ \\
GINIPUB & $5.0(8)$ \\
CITPUB & $6.6(26)$ \\
PHDFAC & $2.0(20)$ \\
PHDSTU & $0.8(23)$ \\
MEDTIME & $7.4(15)$ \\
\hline
\end{tabular}

where:

FACQUAL Scholarly quality of program faculty (scale of 0 to 5 with 0 denoting

"Not sufficient for doctoral education" and 5 denoting "Distinguished").

Total program faculty

FULL Percentage of faculty who are full professors

RESEARCH Percentage of faculty with external research support (1986-92)

PUBFAC Publications per faculty (1988-92)

GINIPUB Gini coefficient for publications per faculty

CITPUB Citations per publication (1988-92)

PHDFAC Total PhDs produced (1988-92) divided by the number of faculty

PHDSTU Total PhDs produced (1988-92) divided by the number of enrolled students in 1992

MEDTIME Median time to degree

Source: Marvin L. Goldberger, Brendan A. Maher, and Pamela E. Flattau, eds. Research Doctorate Programs in the United States.

Washington DC: National Academy Press, 1995. Appendix Tables M 
Table 2A

1993 NRC Scholarly Quality of Program Faculty Equations: Social and Behavioral Sciences

(absolute value $t$ statistics)

\begin{tabular}{|lcccccc|}
\hline \multicolumn{1}{|c}{$\begin{array}{c}\text { Variable } \\
\text { Field }\end{array}$} & Anthropology & Economics & History & $\begin{array}{c}\text { Political } \\
\text { Science }\end{array}$ & Psychology & Sociology \\
\hline FACULTY & $.038(5.2)$ & $.097(5.1)$ & $.077(6.9)$ & $.103(4.5)$ & $.034(6.2)$ & $.030(4.0)$ \\
FACULTY2 & & $-.953(3.5)$ & $-.581(4.4)$ & $-.927(2.6)$ & $-.183(3.2)$ & \\
FULL & $.015(4.7)$ & $.002(0.5)$ & $.010(3.2)$ & $.010(2.6)$ & $.007(3.5)$ & $.010(2.3)$ \\
RESEARCH & $.010(2.6)$ & $.019(4.6)$ & $-.007(0.6)$ & $.020(3.4)$ & $.014(6.6)$ & $.016(3.1)$ \\
PUBFAC & $-.048(0.7)$ & $.204(5.0)$ & $.626(3.6)$ & $.153(1.8)$ & $.087(4.3)$ & $.114(1.6)$ \\
GINIPUB & $-.010(1.5)$ & $.000(0.1)$ & $-.010(2.6)$ & $-.012(2.4)$ & $-.018(7.2)$ & $-.022(2.4)$ \\
CITPUB & $-.099(1.6)$ & $.108(3.5)$ & $.044(2.0)$ & $.127(2.7)$ & $.081(3.7)$ & $.071(2.2)$ \\
PHDFAC & $.231(2.5)$ & $.358(6.4)$ & $.467(5.3)$ & $.235(3.5)$ & $.004(0.3)$ & $.464(3.8)$ \\
PHDSTU & $-.241(1.0)$ & $-.083(1.6)$ & $-.196(3.7)$ & $-.051(0.2)$ & $.017(0.2)$ & $-.976(3.4)$ \\
MEDTMME & $-.111(4.1)$ &. $.169(5.0)$ & $-.039(2.4)$ & $-.069(3.2)$ & $-.029(1.9)$ & $-.069(2.6)$ \\
\hline R & .770 & .873 & .818 & .816 & .854 & .670 \\
$n$ & 69 & 105 & 109 & 96 & 183 & 95 \\
\hline
\end{tabular}

acoefficient has been multiplied by 1000

where:

FACULTY Total program faculty

FACULTY2 Total program faculty squared

FULL Percentage of faculty who are full professors

RESEARCH Percentage of faculty with external research support (1986-92)

Publications per faculty (1988-92)

$\begin{array}{ll}\text { GINIPUB } & \text { Gini coefficient for publications per faculty } \\ \text { CITPUB } & \text { Citations per publication (1988-92) }\end{array}$

PHDFAC Total PhDs produced (1988-92) divided by the number of faculty

PHDSTU Total PhDs produced (1988-92) divided by the number of enrolled students in 1992

MEDTIME Median time to degree

Source: Marvin L. Goldberger, Brendan A. Maher, and Pamela E. Flattau, eds. Research Doctorate Programs in the United States. Washington DC: National Academy Press, 1995. Appendix Tables M 


\section{Table 2B}

1993 NRC Scholarly Quality of Program Faculty Equations: Biological Sciences (absolute value $t$ statistics)

\begin{tabular}{|lcccccc|}
\hline $\begin{array}{l}\text { Field } \\
\text { Variable }\end{array}$ & $\begin{array}{c}\text { Biochem } \\
\text { and Molec }\end{array}$ & $\begin{array}{c}\text { Cell and } \\
\text { Developmental }\end{array}$ & $\begin{array}{c}\text { Ecology, } \\
\text { Evolution, } \\
\text { and Behav. }\end{array}$ & $\begin{array}{c}\text { Molecular and } \\
\text { General Genetics }\end{array}$ & Neuroscience & Physiology \\
\hline FACULTY & $.016(3.5)$ & $.012(2.7)$ & $.014(3.0)$ & $.002(0.8)$ & $.031(2.7)$ & $.055(4.8)$ \\
FACULTY2a & $-.056(2.0)$ & $-.066(2.0)$ & $-.039(1.5)$ & & $-.165(1.6)$ & $-.609(3.8)$ \\
FULL & $.004(1.9)$ & $.006(2.2)$ & $.003(0.9)$ & $-.003(1.0)$ & $.004(1.3)$ & $.001(0.2)$ \\
RESEARCH & $.007(3.6)$ & $.003(1.4)$ & $.013(4.9)$ & $.006(2.4)$ & $.009(2.7)$ & $.004(2.3)$ \\
PUBFAC & $.021(1.6)$ & $.050(3.2)$ & $.089(2.9)$ & $.067(4.2)$ & $-.002(0.1)$ & $.030(3.4)$ \\
GINIPUB &. $.026(5.6)$ & $-.028(6.3)$ & $-.019(2.7)$ & $-.044(6.4)$ & $-.025(3.2)$ & $-.019(3.1)$ \\
CITPUB & $.087(8.4)$ & $.077(7.0)$ & $-.014(0.4)$ & $.047(4.3)$ & $.117(7.2)$ & $.081(6.4)$ \\
PHDFAC & $.120(2.3)$ & $.081(1.4)$ & $.068(1.1)$ & $.084(1.8)$ & $.227(2.0)$ & $-.093(1.2)$ \\
PHDSTU & $.020(0.2)$ & $-.006(0.1)$ & $-.025(0.8)$ & $-.137(1.2)$ & $-.459(2.3)$ & $.062(1.1)$ \\
MEDTIME & $-.011(0.5)$ & $-.038(1.7)$ & $-.054(2.6)$ & $.002(0.2)$ & $-.015(0.4)$ & $-.014(0.8)$ \\
\hline R & .838 & .851 & .693 & .864 & .815 & .834 \\
$n$ & 159 & 135 & 105 & & 78 & 116 \\
\hline
\end{tabular}

acoefficient has been multiplied by 1000

where:

$\begin{array}{ll}\text { FACULTY } & \text { Total program faculty } \\ \text { FACULTY2 } & \text { Total program faculty squared } \\ \text { FULL } & \text { Percentage of faculty who are full professors } \\ \text { RESEARCH } & \text { Percentage of faculty with external research support (1986-92) } \\ \text { PUBFAC } & \text { Publications per faculty (1988-92) } \\ \text { GINIPUB } & \text { Gini coefficient for publications per faculty } \\ \text { CITPUB } & \text { Citations per publication (1988-92) } \\ \text { PHDFAC } & \text { Total PhDs produced (1988-92) divided by the number of faculty } \\ \text { PHDSTU } & \text { Total PhDs produced (1988-92) divided by the number of enrolled students in } 1992 \\ \text { MEDTIME } & \text { Median time to degree }\end{array}$

Source: Marvin L. Goldberger, Brendan A. Maher, and Pamela E. Flattau, eds. Research Doctorate Programs in the United States. Washington DC: National Academy Press, 1995. Appendix Tables N 
Table 2C

1993 NRC Scholarly Quality of Program Faculty Equations: Engineering (absolute value $t$ statistics)

\begin{tabular}{|c|c|c|c|c|c|c|c|c|}
\hline $\begin{array}{l}\text { Field/ } \\
\text { Variable }\end{array}$ & Aerospace & Chemical & Civil & $\begin{array}{c}\text { Computer } \\
\text { Science }\end{array}$ & Electrical & Geoscience & $\begin{array}{l}\text { Material } \\
\text { Science }\end{array}$ & Mechanical \\
\hline FACULTY & $.093(1.7)$ & $.146(4.3)$ & $.044(4.0)$ & $.079(3.9)$ & $.055(6.8)$ & $.027(3.6)$ & $.035(1.9)$ & $.047(4.9)$ \\
\hline FACULTY $2^{a}$ & $-1.555(1.4)$ & $-3.030(3.3)$ & $-266(23)$ & $-.669(2.1)$ & $-.380(4.2)$ & $-.107(1.7)$ & $-250(1.3)$ & $-.374(3.4)$ \\
\hline FULL & $.008(1.5)$ & $-.000(0.1)$ & $.012(4.0)$ & $.000(1.2)$ & $.004(1.8)$ & $.005(1.8)$ & $-.000(0.1)$ & $.007(3.5)$ \\
\hline RESEARCH & $.006(1.1)$ & $.003(1.3)$ & $.007(2.6)$ & $.018(6.5)$ & $.006(3.0)$ & $.009(3.5)$ & $.009(2.3)$ & $.011(4.7)$ \\
\hline PUBFAC & $-.013(0.2)$ & $.065(4.2)$ & $.042(1.6)$ & $.014(0.3)$ & $.062(3.5)$ & $.076(3.5)$ & $.021(2.0)$ & $.043(2.0)$ \\
\hline GINIPUB & $.000(0.0)$ & $-.007(1.3)$ & $-.019(2.6)$ & $-.001(0.1)$ & $-.001(0.1)$ & $-.018(3.4)$ & $-.017(1.7)$ & $-.015(2.8)$ \\
\hline CITPUB & $216(2.8)$ & $.088(2.3)$ & $.073(1.4)$ & $.145(3.8)$ & $.056(1.4)$ & $.028(1.3)$ & $.018(1.6)$ & $.054(1.3)$ \\
\hline PHDFAC & $290(3.5)$ & $.191(5.2)$ & $.233(3.6)$ & $.111(2.1)$ & $.179(4.9)$ & $.101(1.4)$ & $.161(3.7)$ & $.183(4.4)$ \\
\hline PHDSTU & $.190(0.7)$ & $-.057(1.0)$ & $-.154(2.7)$ & $.100(0.5)$ & $-.005(1.7)$ & $.111(0.9)$ & $306(1.8)$ & $.038(0.4)$ \\
\hline MEDTME & $-.098(1.6)$ & $-.095(2.4)$ & $-.096(2.7)$ & $-.043(1.0)$ & $-.065(2.6)$ & $-.055(2.1)$ & $-.073(1.6)$ & $-.031(1.1)$ \\
\hline $\mathbf{R}^{2}$ & .756 & 862 & .812 & .791 & .867 & .854 & .716 & .840 \\
\hline $\mathbf{n}$ & 33 & 92 & 84 & 105 & 125 & 91 & 55 & 107 \\
\hline
\end{tabular}

acoefficient has been multiplied by 1000

where:

FACULTY
FACULTY2
FULL
RESEARCH
PUBFAC
GINIPUB
CITPUB
PHDFAC
PHDSTU
MEDTIME

Total program faculty

Total program faculty squared

Percentage of faculty who are full professors

Percentage of faculty with external research support (1986-92)

Publications per faculty (1988-92)

Gini coefficient for publications per faculty

Citations per publication (1988-92)

Total PhDs produced (1988-92) divided by the number of faculty

Total PhDs produced (1988-92) divided by the number of enrolled students in 1992

Median time to degree

Source: Marvin L. Goldberger, Brendan A. Maher, and Pamela E. Flattau, eds. Research Doctorate Programs in the United States.

Washington DC: National Academy Press, 1995. Appendix Tables K 
Table 2D

1993 NRC Scholarly Quality of Program Faculty Equations: Physical Sciences/Mathematics (absolute value $\mathrm{t}$ statistics)

\begin{tabular}{|lccccr|}
\hline $\begin{array}{l}\text { Field } \\
\text { Variable }\end{array}$ & Astronomy & Chemistry & Mathematics & \multicolumn{1}{l}{ Physics } & \multicolumn{1}{c|}{ Statistics } \\
\hline FACULTY & $.058(2.4)$ & $.046(3.2)$ & $.034(2.9)$ & $.050(6.1)$ & $.107(2.0)$ \\
FACULTY2 & & $-.348(1.6)$ & $-.144(1.5)$ & $-.271(3.4)$ & $-1.607(1.4)$ \\
FULL & $.001(0.1)$ & $.004(1.8)$ & $.004(1.3)$ & $.006(2.3)$ & $.016(3.1)$ \\
RESEARCH & $-.003(0.6)$ & $.008(5.1)$ & $.019(7.1)$ & $.003(1.6)$ & $.018(4.7)$ \\
PUBFAC & $.121(2.8)$ & $.044(5.2)$ & $-.061(1.5)$ & $.014(1.0)$ & $.065(1.5)$ \\
GINIPUB & $-.000(0.0)$ & $-.023(3.3)$ & $-.009(0.8)$ & $-.022(2.7)$ & $.005(0.3)$ \\
CITPUB & $-.026(0.2)$ & $.005(1.0)$ & $-.000(0.1)$ & $.049(4.2)$ & $.002(02)$ \\
PHDFAC & $.322(1.3)$ & $.181(6.9)$ & $.663(6.8)$ & $.324(6.0)$ & $.056(0.5)$ \\
PHDSTU & $-.213(0.4)$ & $-.026(1.1)$ & $.131(2.2)$ & $-.263(1.9)$ & $.226(0.9)$ \\
MEDTME & $-.183(1.8)$ & $-.096(4.0)$ & $-.086(3.1)$ & $-.029(1.0)$ & $-.038(1.0)$ \\
\hline R & .765 & .903 & .813 & .851 & .676 \\
$n$ & 33 & 167 & 131 & 143 & 50 \\
\hline
\end{tabular}

acoefficient has been multiplied by 1000

where:

FACULTY

FACULTY2

FULL

RESEARCH

PUBFAC

GINIPUB

CITPUB

PHDFAC

PHDSTU

MEDTIME

Total program faculty

Total program faculty squared

Percentage of faculty who are full professors

Percentage of faculty with external research support (1986-92)

Publications per faculty (1988-92)

Gini coefficient for publications per faculty

Citations per publication (1988-92)

Total PhDs produced (1988-92) divided by the number of faculty

Total PhDs produced (1988-92) divided by the number of enrolled students in 1992

Median time to degree

Source: Marvin L. Goldberger, Brendan A. Maher, and Pamela E. Flattau, eds. Research Doctorate Programs in the United States. Washington DC: National Academy Press, 1995. Appendix Tables L 
Table 2E

1993 NRC Scholarly Quality of Program Faculty Equations: Arts and Humanities (absolute value $t$ statistics)

\begin{tabular}{|c|c|c|c|c|c|c|c|c|c|c|}
\hline $\begin{array}{c}\text { Field } \\
\text { Variable }\end{array}$ & Art History & Classics & Comp. Lit. & English & French & German & Linguistics & Music & Philosophy & Spanish \\
\hline FACULTY & $.164(4.2)$ & $.255(4.0)$ & $.024(2.4)$ & $.066(5.0)$ & $238(2.3)$ & $.052(2.3)$ & $.038(3.7)$ & $.010(2.4)$ & $.142(3.1)$ & $.082(2.1)$ \\
\hline FACULTY2a & $-2.157(2.1)$ & $-5.240(2.9)$ & & $-.436(2.7)$ & $-6.636(2.0)$ & & & & $-2.263(2.2)$ & $-1.114(1.3)$ \\
\hline FULL & $.015(3.6)$ & $.015(2.1)$ & $.013(1.5)$ & $.000(1.1)$ & $.014(2.2)$ & $.003(0.6)$ & $.011(2.3)$ & $.008(1.9)$ & $.010(2.4)$ & $.010(2.2)$ \\
\hline RESEARCH & $.001(0.3)$ & $.040(0.9)$ & $-.054(0.9)$ & $.007(0.5)$ & $-.016(0.6)$ & $.017(0.4)$ & $.028(5.3)$ & $-.004(0.1)$ & $.010(1.6)$ & $-.006(0.1)$ \\
\hline AWARDF & $578(1.9)$ & $586(1.4)$ & $1.287(1.6)$ & $2.742(7.2)$ & $1.651(2.1)$ & $1.771(1.9)$ & $1.579(2.1)$ & $2.642(5.6)$ & $3.076(7.2)$ & $2.276(2.9)$ \\
\hline PHDFAC & $541(3.9)$ & $.562(1.9)$ & $-.001(0.0)$ & $216(22)$ & $298(1.5)$ & $.175(0.7)$ & $.198(2.0)$ & $.021(0.2)$ & $.052(0.3)$ & $.360(2.4)$ \\
\hline PHDSTU & $-.316(2.0)$ & $.260(0.4)$ & $.139(0.5)$ & $-.034(0.2)$ & $-.095(0.8)$ & $-.403(1.1)$ & $-.668(1.6)$ & $-.028(0.6)$ & $-.137(0.4)$ & $-.126(0.6)$ \\
\hline MEDTMME & $-.071(2.3)$ & $.023(0.5)$ & $-.133(1.6)$ & $-.064(3.0)$ & $-.052(1.1)$ & $-.124(2.8)$ & $-.179(5.5)$ & $-.153(3.6)$ & $-.117(2.9)$ & $-.038(1.1)$ \\
\hline $\mathrm{R}^{2}$ & .839 & .748 & 374 & .684 & .461 & .526 & .673 & .545 & .719 & 305 \\
\hline $\mathbf{n}$ & 38 & 29 & 33 & 126 & 33 & 33 & 41 & 66 & 71 & 52 \\
\hline
\end{tabular}

acoefficient has been multiplied by 1000

where:

FACUITY
FACULTY2
FULL
RESEARCH
AWARDF
PHDFAC
PHDSTU
MEDTIME

Total program faculty Total program faculty squared

Percentage of faculty who are full professors

Percentage of faculty with external research support (1986-92)

Total number of awards and honors per faculty member (1986-92)

Total PhDs produced (1988-92) divided by the number of faculty

Total PhDs produced (1988-92) divided by the number of enrolled students in 1992

Median time to degree

source: Marvin L. Goldberger, Brendan A. Maher, and Pamela E. Flattau, eds. Research Doctorate Programs in the United States. Washington DC: National Academy Press, 1995. Appendix Tables J 
Table 3

Why Isn't Cornell Economics Ranked Among The Top 10 Departments?

\begin{tabular}{|c|c|c|c|c|c|c|c|c|c|}
\hline Institution & $\begin{array}{c}1993 \\
\text { Ratings }\end{array}$ & $\begin{array}{l}\text { Ta } \\
\text { Fac }\end{array}$ & $\begin{array}{l}\% \\
\text { Full }\end{array}$ & $\begin{array}{l}\% \\
\text { Supr }\end{array}$ & $\begin{array}{l}\text { Pub/ } \\
\text { Fac }\end{array}$ & $\begin{array}{l}\text { Gini } \\
\text { Pub }\end{array}$ & $\begin{array}{l}\text { Culd } \\
\text { Pub }\end{array}$ & $\begin{array}{l}\text { PhDs } \\
\text { Fac }\end{array}$ & MYD \\
\hline 1 Chicago & 4.95 & 31 & 81 & 23 & 3.4 & 6.7 & 7.0 & 1.6 & 7.8 \\
\hline 2 Harvard & 4.95 & 44 & 66 & 23 & 6.3 & 4.4 & 3.7 & 2.1 & 6.5 \\
\hline 3 MTT & 4.93 & 28 & 68 & 25 & 5.0 & 7.0 & 4.5 & 1.8 & 5.8 \\
\hline Stanford & 4.92 & 36 & 67 & 28 & 4.4 & 5.3 & 3.7 & 1.4 & 7.1 \\
\hline 5 Princeton & 4.84 & 41 & 61 & 39 & 3.9 & 5.3 & 3.3 & 1.4 & 6.6 \\
\hline 6 Yale & 4.70 & 44 & 68 & 34 & 4.0 & 5.2 & 3.3 & 1.3 & 8.3 \\
\hline 7 Cal-Berkeley & 4.55 & 41 & 71 & 32 & 4.2 & 4.0 & 3.7 & 1.4 & 7.6 \\
\hline Penn & 4.43 & 51 & 61 & 45 & 4.5 & 4.1 & 2.9 & 1.8 & 6.9 \\
\hline 9 Northwestern & 4.39 & 47 & 68 & 51 & 4.2 & 3.6 & 3.4 & 0.7 & 6.7 \\
\hline 10 Minnesola & 4.22 & 18 & 78 & 33 & 2.9 & 10.5 & 1.5 & 1.0 & 7.9 \\
\hline 11 Means of $1-5$ & 4.92 & 36 & 69 & 28 & 4.6 & 5.7 & 4.4 & 1.7 & 6.8 \\
\hline 12 Means of 6-10 & 4.46 & 40 & 69 & 39 & 4.0 & 5.5 & 2.9 & 1.2 & 7 \\
\hline 13 Means 1-10 & 4.69 & 38 & 69 & 33 & 4.3 & 5.6 & 3.7 & 1.5 & 7.1 \\
\hline 14 Comell & 3.56 & 30 & 70 & 33 & 3.1 & 5.0 & 2.1 & 0.8 & 7.4 \\
\hline 15 DIFF & 1.13 & 8.10 & -1.10 & 0.30 & 1.18 & 0.61 & 1.56 & 0.61 & $-0.2 \varepsilon$ \\
\hline 16 SHARE (\%) & & $28^{*}$ & 0 & $1^{*}$ & $21^{*}$ & $\mathbf{0}$ & $15^{*}$ & $19 *$ & $4^{*}$ \\
\hline 17 Unexplained Share & $13 \%$ & & & & & & & & \\
\hline
\end{tabular}

Where

DIFF Mean value of variable for the top ten schools minus the Cornell value of the differential

SHARE Percentage of DIFF attributable to difference in the variable calculated as 100 times coef." $\left(X-X_{c u}\right) /\left(Y-Y_{c u}\right)$ where coef. is the regression coefficient of the characteristic, $X$ is the mean for the top ten institutions, $X_{c u}$ is the Cornell value for the same characteristic, $Y$ is the mean quality rating of the top ten institutions and $Y_{\mathrm{cu}}$ is the Cornell quality rating. The calculation of the share attributable to differences in faculty size generalized the formula to take account of the fact that faculty size appears in the model in both linear and quadratic forms in many fields.

and

SHARE calculation based on coefficient that is statistically significantly different from zero at the .05 level of significance two tail test. 
Appendix Table 1

1993 NRC Scholarly Quality of Program

Faculty Equation for Economics: Logit Modela (absolute value $t$ statistics)

\begin{tabular}{lr}
\hline & \\
FACULTY & $.119(4.7)$ \\
FACULTY2b & $-1.281(3.6)$ \\
FULLb & $3.197(0.7)$ \\
RESEARCHb & $9.816(1.8)$ \\
PUBFAC & $.283(5.4)$ \\
GINIPUBb & $-3.653(0.5)$ \\
CITPUB & $.140(3.4)$ \\
PHDFAC & $.553(7.4)$ \\
PHDSTU & $-.108(1.6)$ \\
MEDTMME & $-.201(4.5)$ \\
\hline & \\
$\overline{\mathbf{R}}^{2}$ & .838 \\
$\mathrm{n}$ & 105 \\
\hline
\end{tabular}

a The dependent variable is $\log \left(R_{\mathbf{i}} /\left(5-R_{\mathbf{i}}\right)\right)$

b The coefficient has been multiplied by 1000 .

See table $2 \mathrm{~A}$ for variable definitions 
Appendix Table 2

Why Isn't Cornell Economics Ranked Among The Top 10 Departments?

\begin{tabular}{|c|c|c|c|c|c|c|c|c|c|c|c|}
\hline & Institution & $\log (R /(5-R))$ & $\begin{array}{c}1993 \\
\text { Ratings }\end{array}$ & $\begin{array}{l}\text { Tot } \\
\text { Fac }\end{array}$ & $\begin{array}{l}\% \\
\text { Full }\end{array}$ & $\begin{array}{c}\% \\
\text { Supp }\end{array}$ & $\begin{array}{l}\text { Pub/ } \\
\text { Fac }\end{array}$ & $\begin{array}{l}\text { Gini } \\
\text { Pub }\end{array}$ & $\begin{array}{l}\text { Citel } \\
\text { Pub }\end{array}$ & $\begin{array}{c}\text { PhDs } \\
\text { Fac }\end{array}$ & MYD \\
\hline 1 & Chicago & 4.60 & $4 . \overline{95}$ & 31 & 81 & 23 & 3.4 & 6.7 & 7 & 1.6 & 7.8 \\
\hline 2 & Harvard & 4.60 & 4.95 & 44 & 66 & 23 & 6.3 & 4.4 & 3.7 & 2.1 & 6.5 \\
\hline 3 & MIT & 4.25 & 4.93 & 28 & 68 & 25 & 5 & 7 & 4.5 & 1.8 & 5.8 \\
\hline 4 & Stanford & 4.12 & 4.92 & 36 & 67 & 28 & 4.4 & 5.3 & 3.7 & 1.4 & 7.1 \\
\hline 5 & Princeton & 3.41 & 4.84 & 41 & 61 & 39 & 3.9 & 5.3 & 3.3 & 1.4 & 6.6 \\
\hline 6 & Yale & 2.75 & 4.7 & 44 & 68 & 34 & 4 & 5.2 & 3.3 & 1.3 & 8.3 \\
\hline 7 & Cal-Berkeley & 2.31 & 4.55 & 41 & 71 & 32 & 4.2 & 4 & 3.7 & 1.4 & 7.6 \\
\hline 8 & Penn & 2.05 & 4.43 & 51 & 61 & 45 & 4.5 & 4.1 & 2.9 & 1.8 & 6.9 \\
\hline 9 & Northwestern & 1.97 & 4.39 & 47 & 68 & 51 & 4.2 & 3.6 & 3.4 & 0.7 & 6.7 \\
\hline 10 & Minnesota & 1.69 & 4.22 & 18 & 78 & 33 & 2.9 & 10.5 & 1.5 & 1 & 7.9 \\
\hline 11 & Means of 1-5 & 4.12 & 4.92 & 36 & 68.6 & 27.6 & 4.6 & 5.74 & 4.44 & 1.66 & 6.76 \\
\hline 12 & Means of $6-10$ & 1.99 & 4.4 & 39.25 & 69.5 & 40.25 & 3.95 & 5.55 & 2.88 & 1.23 & 7.28 \\
\hline 13 & Means of $1-10$ & 2.72 & 4.69 & 38.1 & 68.9 & 33.3 & 4.28 & 5.61 & 3.7 & 1.45 & 7.12 \\
\hline 14 & $\begin{array}{c}\text { Cornell } \\
\text { University }\end{array}$ & 0.91 & 3.56 & 30 & 70 & 33 & 3.1 & 5 & 2.1 & 0.8 & 7.4 \\
\hline 15 & DIFF & 1.81 & 1.13 & 8.1 & -1.1 & 0.3 & 1.18 & 0.61 & 1.6 & 0.65 & -0.28 \\
\hline 16 & SHARE (\%) & & & $17^{*}$ & 0 & 0 & $18^{*}$ & 0 & $12^{*}$ & $20^{*}$ & $3^{*}$ \\
\hline 17 & $\begin{array}{c}\text { Unexplained } \\
\text { Share }\end{array}$ & & $30 \%$ & & & & & & & & \\
\hline
\end{tabular}

Where

DIFF Mean value of variable for the top ten schools minus the Comell value of the differential

SHARE Share of DIFF attributable to difference in the variable calculated as coef." $\left(X-X_{\mathrm{cu}}\right) /\left(Y-Y_{\mathrm{cu}}\right)$ where coef. is the regression coefficient of the characteristic, $X$ is the mean for the top ten institutions, $X_{c u}$ is the Cornell value for the same characteristic, $Y$ is the mean quality rating of the top ten institutions and $Y_{\mathrm{cu}}$ is the Cornell quality rating.

and

SHARE calculation based on coefficient that is statistically significantly different from zero at the .05 level of significance two tail test. 